\title{
Harmful Effects in Personal Assistants' Client Transfer Situations
}

\author{
Anette Lind ${ }^{1}$ and Gunvor Gard ${ }^{*}, 2$ \\ ${ }^{1}$ Luleå Community Service, Luleå, Sweden \\ ${ }^{2}$ Dept of Health Sciences, Luleå University of Technology, 97187 Luleå, Sweden
}

\begin{abstract}
The aim of this study was to describe personal assistants' risks for harmful effects in client transfer situations at work. Observation and assessment of their working postures in transfer situations were performed by the Swedish ergonomic regulations concerning "red flags" (AFS 1998:1), by video recordings and by biomechanical analysis. The results showed that among eight home care assistants, four assistants had a low-back posture in client transfer situations which was flexed and/or rotated $>60$, classified as a harmful effect, a red flag, with a high risk for musculoskeletal workrelated symptoms and disorders and the other four had a risk for harmful effects, yellow flags. The harmful effects were noted in highly flexed and rotated working postures when technical equipment was not used or not possible to use anthropometrically correct. All eight personal assistants' neck flexion indicated yellow flags, thus there were risks for harmful effect in the neck.
\end{abstract}

Keywords: Harmful effects, patient transfer, personal assistant, home care.

\section{INTRODUCTION}

The frequency of persons needing home care from personal assistants' is increasing. There are about 130000 personal assistants working in Sweden [1]. They have monotonous working postures, heavy lifting and a lot of client transfer situations in their work. To work in a client's home implies high physical workload according to ergonomic principles and regulations [1-3]. The psychosocial workload is also high due to stressful work situations. In addition they also perceive threatening situations at work and/or during traveling from work late in the evenings [1].

In daily practice, there are high demands on personal assistants' ability to adapt their working postures to their clients' needs, physical abilities and psychosocial conditions, which influence how the work can be performed. Private homes also differ concerning the opportunity to have space to move freely, which influence the physical workload. For example, patient transfer from lying to sitting on a bed and/or moving from sitting in the bed to sitting in a chair is very common within home care. In such transfer situations different technical equipment can be used as assistive devices, for example a mobile lift, functioning as a mobile chair, to transfer a patient. Such equipment is necessary to use in home care when a client is unable to participate in necessary transfer situations. To reduce the risks for harmful effects it is important to work without too much bending, stretching or rotating of the body. Such postures increase the risk for harmful effects on the body [1]. Time pressure can also increase the physical strain. Young person's back discs

Address correspondence to this author at the Department of Health Sciences, Luleå University of Technology, 97187 Luleå, Sweden;

Tel: 46-46-2321196; E-mail: Gunvor.Gard@1tu.se can afford a physical load by approximately $8000 \mathrm{~N}$, and elderly people can afford about $4000 \mathrm{~N}$ [4].

Risk assessment is important and has to be performed to ensure a good working environment. This includes for example to fulfill demands on enough space to move freely in transfer situations. It is important that personal assistants' can move freely and use work equipment in a correct way [1]. The risk for musculoskeletal disorders and harmful effects at work can be reduced by the use of equipment in client transfer situations $[3,5,6]$. A good transfer technique reduces the physical strain and risk for harmful effects by the client's active cooperation in the situation [7]. It is possible to learn and practice a correct transfer technique, which has been shown to reduce neck and back strain [7, 8]. Supervisors within home care organizations have to offer the staff education and practice in transfer techniques [1]. When the staff use transfer techniques in a correct way, the clients may feel more secure in the transfer situations. Heavy manual lifting and heavy workload has to be avoided and the work organized so that musculoskeletal disorders can be prevented [9].

According to the EU-standard in transfer techniques there are four important steps in the training of transfer techniques: 1) a basic workplace analysis as a basis, 2) knowledge about transfer techniques 3) practical training opportunities in a real work situation and 4) to learn how to evaluate the transfer technique [9]. An EU-standard is a standard adopted by one of three recognized European Standardisation Organisations (ESOs): CEN, CENELEC or ETSI. It is produced by all interested parties through a transparent, open and consensus based process. Transfer techniques can be trained by the use of video recordings of work in real situations and observations and discussions of the working technique [9]. 
There is an increased risk of harmful effects on the body when moving a patient in bed manually, when transferring a client from bed to wheelchair and when lifting a client from the floor $[8,10]$. To lift a patient by a shoulder-grip implies a high physical strain on the home care assistant [5]. There is evidence of high physical strain in shoulder and back region among staff in manual transferring of clients in different situations for example from a bed to a chair [11]. There are also risks with static work, with or without lifting clients. The more flexed working posture, the higher physical strain [12]. According to the NIOSH recommendations concerning axial strain [13], it is harmful to work with the low back spine in highly flexed position more than two minutes frequently during a working day. The axial strain should not exceed $3432 \mathrm{~N}(350 \mathrm{~kg})$ in the low back, otherwise harmful effects might occur. Lifting without the use of lifting devices or using only a lifting belt may imply body postures with risks for harmful effects exceeding $3432 \mathrm{~N}$. Using mobile lifting devices for example a roof-based lifting equipment to support a patient transfer may reduce the physical strain on the back [14]. Harmful effects for the low-back occur when working in a posture with the trunk flexed more than 60 degrees, particularly if the spine is rotated and flexed $[12,15]$.

Risk assessments shall be performed for each client before the work begins and when the conditions change. These assessments shall be performed in all workplaces, also when the workplace is a client's home, to assure that all workers have an acceptable working environment [1].

In summary, earlier research concerning patent transfer have shown that the most harmful situations are to transfer a client from lying to sitting in bed and from sitting in bed to sitting in a wheelchair $[5,8,10,11]$. Therefore, these work situations need to be further studied. As a high low-back flexion is known to be an indicator of a harmful effect [15], the low-back flexion needs to be acknowledged in the present study.

The aim of this study was to describe personal assistants' risks for harmful effects in client transfer situations at work.

\subsection{Research Questions}

1. Were there any harmful effects noted during patient transfer?

2. How was the low back flexion during the patient transfer situations?

\section{MATERIALS AND METHODOLOGY}

\subsection{Participants}

Eight clients and eight personal assistants from a private assistance company in the north of Sweden participated in the study. Inclusion criteria were: Each client must have a need of personal assistance and a need of help in transfer situations. The clients' age ranged from 41-68 years with a mean age of 59 years; five were men and 3 women. They had different physical restrictions, but all needed help in transfer situations from a personal assistant. Some of them were transferred only with little ergonomic equipment, while others were moved to bed by a lift from the roof and could not participate at all. Different ergonomic equipment were used such as movable bed, sliding aids, lifting slings, mobile and ceiling lifts, transportation platforms, sit to stand lift, manual wheelchair and comfort wheelchair.

Eight personnel assistants participated in the study and they had different knowledge of transfer techniques at work and had worked within home health care during a variety of time.

\subsection{Procedure}

First the company owner was informed about the study and informed the supervisors. They asked clients about participation and clients interested to participate gave their informed consent in written form. These patients' the personnel assistants were then asked about participation and also gave their informed consent in written form to the researchers.

\subsection{Methodology}

The methodologies used were observation and assessments of the personnel assistants' trunk postures in two transfer situations, performed according to the Swedish ergonomic regulations, AFS 1998:1 [15], where harmful effects, "red flags" were identified. Red flags indicate a harmful effect, that is working with flexed back without freedom to move or working with a rotated back without freedom to move or at the same time flexed and rotated back with strongly reduced freedom to move (Table 1). Yellow flags indicate that the working posture is at risk and has to be further assessed (Table 1). Green flags indicate an acceptable working posture (Table 1).

Low back flexion in two transfer situations, lying in bed to sitting and sitting in bed to sitting in a wheelchair, were analyzed biomechanically according to Jonsson [16] for all assistants, in total 16 assessments. According to the ISO standard, a low back flexion more than 60 degrees indicates a harmful effect and a flexion between 20-60 degrees indicates that there are risks for harmful effects [17]. Harmful effects indicate high strain on muscles and joints increasing the risks for musculoskeletal disorders and workrelated disorders.

\section{RESULTS}

\subsection{Harmful Effects in Body Regions During Patient Transfer}

All eight personal assistants had a risk for harmful effect in neck flexion, indicated by yellow flags, thus a neck flexion between $20-60^{\circ}$ (Table 2). Harmful effects in the lumbar spine, red flags, were indicated for four of the personal assistants. They had working postures with $>60^{\circ}$ flexion and rotation. Risks for harmful effects in the lumbar spine, yellow flags, were noted for the other four personal assistants (Table 2). One personal assistant had a harmful effect, a red flag concerning arm/shoulder postures, two had risks for harmful effects, yellow flags, when working with their hands below knee height periodically under the work shift. The other five personal assistants had an acceptable work posture (green flags) (Table 2). Concerning the work posture for the legs, only one personal assistant had not enough space for legs and feet, which can be a risk for harmful effect. The other seven personal assistants had no problems with the work posture for legs; they had a nonslip, 
Table 1. The Swedish Working Environment Regulations Concerning Harmful Effects, AFS 1998:1 Concerning Working Postures in Different Body Regions [15]

\begin{tabular}{|c|c|c|c|}
\hline & Red Harmful Effect & Yellow Risk for Harmful Effect & Green \\
\hline Standing/Walking & $\begin{array}{l}\text { One of these factors is present during } \\
\text { a significant part of the work shift }\end{array}$ & $\begin{array}{l}\text { One of these factors is present } \\
\text { intermittently } \\
\text { during the shift }\end{array}$ & $\begin{array}{l}\text { These factors are present } \\
\text { during a significant part of the work } \\
\text { shift }\end{array}$ \\
\hline Neck & $\begin{array}{l}\text { - bent posture, }>60 \text {, with no freedom of } \\
\text { movement } \\
\text { - twisted posture, with no } \\
\text { freedom of movement } \\
\text { - bent and twisted } \\
\text { posture } \\
\text { - highly reduced freedom of movement }\end{array}$ & $\begin{array}{l}\text { - bent posture } 20-60 \text {,with no } \\
\text { freedom of movement } \\
\text { - twisted posture, with no } \\
\text { freedom of movement } \\
\text { - bent and twisted } \\
\text { posture } \\
\text { - highly reduced freedom of } \\
\text { movement }\end{array}$ & $\begin{array}{l}\text { - upright posture, } \\
\text { with freedom of } \\
\text { movement }\end{array}$ \\
\hline Lumbar spine & $\begin{array}{l}\text {-- bent posture, }>60 \text { with no freedom } \\
\text { of movement } \\
\text { - twisted posture, with no } \\
\text { freedom of movement } \\
\text { - bent and twisted } \\
\text { posture } \\
\text { - highly reduced freedom of movement } \\
\text {-unstable or sloping } \\
\text { floor }\end{array}$ & $\begin{array}{l}\text { - bent posture } 20-60 \text { with no } \\
\text { freedom of movement } \\
\text { - twisted posture, with no } \\
\text { freedom of movement } \\
\text { - bent and twisted } \\
\text { posture } \\
\text { - highly reduced freedom of } \\
\text { movement } \\
\text { unstable or sloping } \\
\text { floor }\end{array}$ & $\begin{array}{l}\text { - upright posture, } \\
\text { with freedom of } \\
\text { movement } \\
\text { - opportunity to } \\
\text { change to seated } \\
\text { position }\end{array}$ \\
\hline Shoulder/arms & $\begin{array}{l}\text { - hand at or above } \\
\text { shoulder height } \\
\text { - hand at or below knee } \\
\text { height } \\
\text { - hand more than } 3 / 4 \\
\text { arm's length from body }\end{array}$ & $\begin{array}{l}\text { - hand at or above } \\
\text { shoulder height } \\
\text { - hand at or below knee } \\
\text { height } \\
\text { - hand more than } 3 / 4 \\
\text { arm's length from body }\end{array}$ & $\begin{array}{l}\text { - working height } \\
\text { and reach adapted } \\
\text { to task and worker }\end{array}$ \\
\hline Legs & $\begin{array}{l}\text {-insufficient space for } \\
\text { legs and feet } \\
\text { - unstable floor } \\
\text { - sloping floor } \\
\text { - use of pedal work }\end{array}$ & $\begin{array}{l}\text {-insufficient space for } \\
\text { legs and feet } \\
\text { - unstable floor } \\
\text { - sloping floor } \\
\text { - use of pedal work }\end{array}$ & $\begin{array}{l}\text { - freedom of } \\
\text { movement on nonslip, } \\
\text { even and level } \\
\text { floor } \\
\text { - no pedal work by foot } \\
\text { - opportunity to } \\
\text { Change to sitting } \\
\text { position }\end{array}$ \\
\hline
\end{tabular}

smooth horizontally support during substantial part of work shift (Table 2).

\subsection{Low Back Flexion in the Transfer Situations}

One personal assistant had a low back flexion of $65^{\circ}$ in client transfer from lying in a bed to sitting position on the bed, indicating a harmful effect. For the others the low-back flexion varied between $25-60^{\circ}$ indicating a risk for harmful effect. The mean value of the low back flexion was $47.5^{\circ}$ for all personal assistants (Table $\mathbf{3}$ ).

When the personal assistants assisted the clients from sitting on a bed to sitting in a wheelchair seven personal assistants had a low back flexion between $35-60^{\circ}$ and one had a low back flexion of $70^{\circ}$. The mean value of low back flexion was $50^{\circ}$ for all personal assistants (Table 4).

\section{DISCUSSION}

Harmful effects or risk for harmful effects in the lowback spine were observed in all eight personal assistants. They had a fairly high trunk flexion, varying between 25 $60^{\circ}$, one assistant had a trunk flexion of $>60^{\circ}$ during client transfer from lying to sitting position, indicating a clear harmful effect in the trunk. According to the ISO standard [12] and Swedish ergonomic regulations [15] a harmful effect in the low back is defined as a trunk flexion and/or rotation $>60^{\circ}$ and a definition also used in the present study. A harmful effect implies a high risk for musculoskeletal work-related symptoms and disorders [12]. There were also risks of harmful effects in the neck, "yellow flags" were noted according to AFS 1998:1 [15] for all eight personal assistants. An earlier study has confirmed high biomechanical load when transferring clients from sitting to 
Table 2. Frequency of Personal Assistants with Harmful Effects (Red), Risk for Harmful Effects (Yellow) and No Harmful Effects (Green) in Working Postures in Different Body Regions when Transferring Clients from Lying in Bed to Sitting According to the Swedish Regulations Concerning Harmful Effects in Different Working Postures AFS 1998:1 (15). N=8

\begin{tabular}{|c|c|c|c|}
\hline Neck & & $\begin{array}{l}\text { - neck flexion } 20-60 \text { with no freedom of movement } \\
\text { ( } 3 \text { assistants) } \\
\text { - bent and twisted posture ( } 5 \text { assistants) }\end{array}$ & \\
\hline Lumbar spine & $\begin{array}{l}\text {-bent posture }>60 \text {, with no freedom of movement ( } 3 \text { assistants) } \\
\text { - bent }>60 \text { and twisted } \\
\text { posture ( } 1 \text { assistant })\end{array}$ & $\begin{array}{l}\text { Flexed } 20-60^{\circ} \text { lumbar spine } \\
(3 \text { assistants }) \\
\text { Flexed } 20-60^{\circ} \text { and rotated lumbar spine } \\
(1 \text { assistant })\end{array}$ & \\
\hline $\begin{array}{l}\text { Shoulder/arms } \\
\text { /hand }\end{array}$ & $\begin{array}{l}\text { Hand more than } 3 / 4 \\
\text { arm's length from body } \\
\text { (1 assistant) }\end{array}$ & $\begin{array}{l}\text { Hand at or below knee height } \\
\text { ( } 2 \text { assistants) }\end{array}$ & $\begin{array}{l}\text { No harmful effect } \\
\text { (5 assistants) }\end{array}$ \\
\hline
\end{tabular}

standing position [8]. It has been shown that the use of transfer equipment can reduce the risk for musculoskeletal symptoms and disorders in such situations [3,5]. It has also been confirmed that the physical strain on the low back spine is high in manual client transfer situations [11], when lifting a client, and/or assisting a client to move from sitting to standing, or when changing position in a wheelchair and/or in a bed [8]. For the personal assistants in the present study, to transfer a client from a lying position to a sitting position implied a harmful effect when the trunk was flexed $>60^{\circ}$. If the client was unable to participate it is even more risky. Such work situations increase the risk for chronic low-back problems.

Table 3. The Personal Assistants Low Back Flexion when Transferring a Client from Lying in Bed to Sitting Position. According to the ISO Standard [17] a Low Back Flexion $>60^{\circ}$ Indicates a Harmful Effect, a Flexion Between 20-60 ${ }^{\circ}$ Indicates a Risk for Harmful Effect and a Flexion Between 0-20 Indicates No Harmful Effect

\begin{tabular}{|c|c|c|c|}
\hline Assistant & $\mathbf{0 - 2 0 ^ { \circ } \text { Flexion }}$ & $\mathbf{2 0 - 6 0}^{\circ}$ Flexion & $>\mathbf{6 0}^{\circ}$ Flexion \\
\hline \hline $\mathrm{Nr}$ 1 & & $55^{\circ}$ & \\
\hline $\mathrm{Nr} 2$ & & $45^{\circ}$ & \\
\hline $\mathrm{Nr} 3$ & & $60^{\circ}$ & \\
\hline $\mathrm{Nr} 4$ & & $35^{\circ}$ & \\
\hline $\mathrm{Nr} 5$ & & $25^{\circ}$ & \\
\hline $\mathrm{Nr} 6$ & & $55^{\circ}$ & \\
\hline $\mathrm{Nr} 7$ & & & $65^{\circ}$ \\
\hline $\mathrm{Nr} 8$ & & $40^{\circ}$ & \\
\hline
\end{tabular}

It is important to increase the evidence about harmful effects in different transfer situations and to implement the
Table 4. The Personal Assistants Low Back Flexion when Transferring a Client from Sitting in Bed to Sitting in a Wheel-Chair. According to the ISO Standard (17) a Low Back Flexion $>6^{\circ}$ Indicates a Harmful Effect, a Flexion Between 20-60 ${ }^{\circ}$ Indicates a Risk for Harmful Effect and a Flexion Between 0-20 ${ }^{\circ}$ Indicates No Harmful Effect

\begin{tabular}{|c|c|c|c|}
\hline Assistant & $\mathbf{0 - 2 0}^{\circ}$ Flexion & $\mathbf{2 0 - 6 0}^{\circ}$ Flexion & $\mathbf{> 6 0}^{\circ}$ Flexion \\
\hline \hline $\mathrm{Nr} 1$ & & $35^{\circ}$ & \\
\hline $\mathrm{Nr} 2$ & & & $70^{\circ}$ \\
\hline $\mathrm{Nr} 3$ & & $55^{\circ}$ & \\
\hline $\mathrm{Nr} 4$ & & $40^{\circ}$ & \\
\hline $\mathrm{Nr} 5$ & & $50^{\circ}$ & \\
\hline $\mathrm{Nr} 6$ & & $55^{\circ}$ & \\
\hline $\mathrm{Nr} 7$ & & $60^{\circ}$ & \\
\hline $\mathrm{Nr} 8$ & & $35^{\circ}$ & \\
\hline
\end{tabular}

knowledge received in the home care and clinical context, so personal assistants and healthcare personal can use it. They have to understand basic ergonomic principles and how to use these principles in different transfer situations. Body awareness exercises can also be useful for personal assistants as well as to learn how to identify signals of pain and to avoid working postures provoking pain. Transfer situations which are problematic and difficult to perform may be further studied and evaluated. Opportunities for the home care assistants to train and prepare for unexpected transfer situations, for example when a client is tired and exhausted, can be arranged as competence development. According to Marras [17], when a risk for a harmful effect is identified, it is recommended to perform a risk evaluation. Physiotherapists and occupational therapists may also screen each client's home environment and perform a risk 
evaluation before sending the home care assistant to work in a client's home. To learn how to perform a safe client transfer is a basic motor learning that is important to learn for all staff working in clients' homes according to the European Union and earlier research $[9,18,19]$. Ergonomic competence and clinical expertise are required for those who educate other professionals in transfer techniques [9]. The motor learning requires followups by competent personnel [9]. Transfer techniques have to be included in the safety practices within each home care organization.

What recommendations can be done to reduce harmful effects in transfer situations? First it is important to have the opportunities to perform the transfer according to ergonomic principles [15] with adjustable beds and equipment that can be adjusted according to the personal assistants' anthropometric measures. Enough working space is also needed, to move freely around technical aids and clients in the transfer situations [1]. On the individual level each assistant needs good physical strength, endurance and body awareness.

As the frequencies of elderly people are increasing in many European countries, home care will be increasingly needed. It is important to promote as healthy ageing as possible, where elderly have the opportunity to maintain their functional capacities by daily physical activity. The rehabilitation at home has to include a variety of technical equipments to assist in client transfer situations. The home care personnel has to focus on empowering their clients to increase participation in transfer situations to promote client quality of life as well as their own working environment. We recommend further studies of this topic for example qualitative studies of what clients mean by a safe transfer situation.

\section{CONCLUSIONS}

Concerning low back flexion, four of the eight home care assistants had a harmful effect, a red flag, in client transfer situations with their low back flexed and/or rotated $>60^{\circ}$, with a high risk for musculoskeletal work-related symptoms and disorders and the other four had a risk for harmful effects, yellow flags.

The harmful effects were noted in highly flexed and rotated working postures when technical equipment was not used or not possible to use anthropometrically correct.

All eight personal assistants' neck flexion indicated yellow flags, thus there were risks for harmful effect in the neck.

\section{CONFLICT OF INTEREST}

The authors confirm that this article content has no conflict of interest.

\section{ACKNOWLEDGEMENTS}

\section{REFERENCES}

[1] Swedish Work Environment Authority, Home care and personal assistance in a good working environment 2009. Available from: www.av.se

[2] Larsson A, Karlqvist L, Westerberg M, Gard G. Identifying work ability promoting factors for home care aides and assistant nurses. BMC Musculoskel Dis 2012; 13: 1

[3] Nelson A, Matz M, Chen F, Siddhartan K, Lloyd J, Fragala G. Development and evaluation of a multifaceted ergonomics program to prevent injuries associated with patient handling tasks. Int J Nurs Stud 2006; 43(6): 717-33.

[4] Daynard D, Yassi A, Cooper JE, Tate R, Norman R, Wells R. Biomechanical analysis of peak and cumulative spinal loads during simulated patient handling activities: a sub study of a randomized controlled trial to prevent lift and transfer injury of health care workers. Appl Ergon 2001; 32: 199-214.

[5] Owen BD. Teaching students safer methods of patient transfer. Nurse Educ 2000; 25(6): 288-93.

[6] McGill SM, Kavcic NS. Transfer of the horizontal patient: the effects of a friction reducing assistive device of low back mechanics. Ergonomics 2005; 48 (8): 915-29.

[7] Tamminen-Peter L. Can improved transferring skills reduce muscle strain while assisting a geriatric patient from wheelchair to bed? 14th International World Physical Therapy Congress. Barcelona, Spain 2003.

[8] Schibye B, Skotte J. The mechanical loads on the lowback during different patient handling tasks. In proceedings of the IE A/HFES 2000 Congress. Santa Monica, California: The Human factors and ergonomic society 2000; 5: 785-8.

[9] Johnsson C, Carlsson R, Lagerström M. Evaluation of training in patient handling and moving skills among hospital and home care personnel. Ergonomics 2002; 45(12): 850-65.

[10] Smedley J, Egger P, Cooper C, Coggon D. Manual handling activities and risk of lowback pain in nurses. Occup Environ Med 1995; 52(3):160-3

[11] Garg A, Owen B, Beller D, Banaag J. A biomechanical and ergonomic evaluation of patient transferring tasks: bed to wheelchair and wheelchair to bed. Ergonomics 1991; 34(3): 289-312.

[12] Brinkhoff A, Knibbe N. The ergostat program pilot study of an ergonomic intervention to reduce static load for caregivers. Professional Safety 2003: 32-9.

[13] National Institute of Occupational Safety and Health. Work practises guide for manual lifting. Technical report. Cincinatti, OH: US Department of Health and Human services, NIOSH 1981. Report No.81-122.

[14] Zhuang Z, Stobbe TJ, Hsiao H, Collins JW, Hobbs GR. Biomechanical evaluation of assistive devices for transferring residents. Appl Ergon 1999; 30: 285-94

[15] AFS 1998. Ergonomic regulations for working postures and movements. National Institute for Occupational Health and Safety, Solna, Sweden 1998.

[16] Jonsson, B. The human being at work. In: Lundgren N, Luthman G, Elgstrand Kl, Eds. Functional anatomy, anthropometrics and biomechanics. Stockholm: Almqvist \& Wiksell 1987.

[17] Marras S, Karwovski W. Occupational ergonomics: principles of work design. Boca Raton: CRC Press 2003

[18] Hignett S, Fray M, Rossi MA, et al. Implementation of the Manual Handling Directive in the healthcare industry in the European Union for patient handling tasks. Int J Ind Ergonom 2007; 37(5): 415-23.

[19] Hignett S, Crumptom E, Ruszala S, Alexander P, Fray M, Fletcher M. Evidence-based patient handling tasks, equipment and interventions. Routledge, London 2003.

Declared none. 